\title{
Eating behaviours and BMI in women with polycystic ovary syndrome
}

\author{
Y. Jeanes, S. Barr, K. Sharp and S. Reeves \\ School of Human and Life Sciences, Roehampton University, Holybourne Avenue, London SW15 4JD, UK
}

Polycystic ovary syndrome (PCOS) affects $\leq 10 \%$ of women of reproductive age in the UK and obesity is a common feature of this syndrome. Food craving, emotional eating and uncontrolled eating have all been anecdotally reported by women with PCOS ${ }^{(1,2)}$. The present study aims to describe the eating behaviours and snacking habits in women with PCOS and investigate their relationship with BMI.

Twenty-four women (aged 31.5 (SD 6.9) years) completed a $3 \mathrm{~d}$ food diary and the three-factor eating questionnaire (TFEQ-R18) ${ }^{(3)}$; these data were analysed to provide eating frequency and emotional eating score, uncontrolled eating score and cognitive restraint score respectively. Eating episodes were calculated by splitting foods into subcategories of drinks, mixed meals and savoury or sweet snacks. Snacks were classified as foods consumed between meals. Weight and height were measured and BMI calculated. BMI was split into categories of $<25 \mathrm{~kg} / \mathrm{m}^{2}, 25-29.9 \mathrm{k} / \mathrm{gm}^{2}$ and $>30 \mathrm{~kg} / \mathrm{m}^{2}$.

The mean BMI of women with PCOS was 29.1 (SD 5.6) $\mathrm{kg} / \mathrm{m}^{2}$; there were six of normal weight, eleven were overweight and seven were obese. Eighteen $(75 \%)$ had a waist circumference $\geq 88 \mathrm{~cm}$, denoting a substantially increased risk to health ${ }^{(4)}$. The mean score for emotional eating was 59 (SD 32), uncontrolled eating score 43(SD 24) and cognitive restraint score 39 (SD 21).

\begin{tabular}{lcc}
\hline Category & Mean & SD \\
\hline Eating frequency including drinks (episodes per d) & 9 & 2.7 \\
Eating frequency excluding drinks (episodes per d) & 5 & 1.5 \\
Sweet snacks (episodes per d) & 2 & 1.3 \\
Savoury snacks (episodes per d) & 0.6 & 0.6 \\
\hline
\end{tabular}

Emotional eating score and BMI were positively related $(r 0.53, P=0.01)$ as was uncontrolled eating score and $\mathrm{BMI}(r 0.47, P=0.04)$. These findings are similar to previous findings reported in healthy women ${ }^{(5)}$. There was a trend towards a significantly greater emotional eating score in overweight and obese women compared with lean women (27 (SD 12) v. 33 (SD 8) respectively; $P=0.08$ ). Additionally, there was a trend towards a relationship between number of eating episodes (excluding drinks) and uncontrolled eating score ( $r$ 0.42, $P=0.06$ ). There was no correlation between eating frequency and BMI, which is in agreement with the findings of a study in healthy adults $^{(6)}$.

The present study is the first to report the eating behaviours in women with PCOS and relate them to BMI. Although the study population is small, it is imperative to identify the incidence and severity of disordered eating in this population to allow dietary information for this population to be more effectively tailored to help maximize the success of lifestyle interventions.

1. Herriot A, Whitcroft S \& Jeanes Y (2008) J Hum Nutr Diet 21, 337-345.

2. Bailey S (2006) Successful Lifestyle Change and Polycystic Ovary Syndrome. Bedford, Beds.: Bedford Hospital NHS Trust.

3. Stunkard AJ \& Messick S (1985) J Psychosom Res 29, 71-83.

4. World Health Organization (2000) Obesity: Preventing and Managing the Global Epidemic. Technical Report Series no. 894. Geneva: WHO.

5. van Strein T, Frijter JE, Roosen RG et al. (1985) Addic Behav 10,333-343.

6. Hampl JS, Heaton CLB \& Taylor CA (2003) J Hum Nutr Diet 16, 3-11. 